\title{
DECELERATION INJURIES OF HEART AND LUNG
}

\author{
Eric Samuel, M.D., F.R.C.S., F.R.C.P.E., F.F.R., D.M.R.E. \\ Radiodiagnostic Department, Royal Infirmary, Edinburgh, 3
}

THE advent of relatively extensive and high-speed motoring has posed a new problem for medical diagnosis and care, namely, the diagnosis and treatment of deceleration injuries. The figures of deaths from motor car accidents in the U.S.A. make salutary reading-1946, 34,000 deaths; 1954, 36,000, and the estimate by the National Safety Council that 1966 will produce 53,000 deaths (Woodward, I957). In this country the total number of casualties recently announced for I 962 were 341,696 and deaths numbered 6,709 . If the basis of 10 injured to 1 killed is taken it will be seen that these figures constitute a problem as important to medical care as cancer or arteriosclerosis.

Braunstein (1957) quotes the figure of $1,000,000$ injured annually in the U.S.A. and quite a large proportion of these cases are the results of deceleration injuries. Livingstone (1954), in reporting $\mathbf{I}, 475$ victims of automobile collisions from 1949 to 1954 , who had been under the care of a group of doctors in Cambridge, Mass., noted that the commonest explanation pointed to an inability of the occupant to control his motion in relation to that of the automobile at the time of collision.

In a detailed analysis of the various regions of the body involved, head injuries, with $72.3 \%$, were the most frequent, but only $3 \%$ of these injuries were classed as dangerous and an additional $3 \%$ were fatal. $43.8 \%$ of head injuries are associated with injuries to other regions.

Injuries to the thorax and thoracic spine were third in frequency and constituted $36.6 \%$ but according to Livingstone they represented the second highest percentage of dangerous and fatal injuries. The majority of injuries affected the thoracic cage and consisted of fractured ribs and sternum, but $10 \%$ of all chest injuries were due to a crushed chest with a corresponding high fatality rate.

The thorax and its contained structures are especially vulnerable to deceleration injuries and

Based on a lecture delivered to the Royal Army Medical College, Millbank, February 1963. in many instances of multiple injuries they are, in fact, the immediate cause of death. As many of these deaths are preventable by early treatment, and as the basis of any successful treatment is accurate and correct diagnosis, it is essential that everyone should be alerted to the importance of accurate and early diagnosis.

As diagnosis is, in most instances, based on radiology and as frequently expert radiological opinion is not always immediately available it is important that all concerned should understand the basic principles of X-ray interpretation of traumatic chest cases. The findings presented are based on the interpretation of the chest films of a number of cases of deceleration injuries which have been admitted to the Royal Infirmary Edinburgh, over the last two years.

Many chest injuries are associated with othefof injuries involving the skull and extremities, which hamper full investigation of the chest condition. A further difficulty is that the radiological investigation is, because of the patient's poor general condition, carried out using a bedside unit and the technical quality of the films is relatively poor and this enhances the difficulties of diagnosis.

\section{Classification}

Deceleration injuries may be classified into:-

(a) Immediate results.

(i) Impact injuries.

(ii) Momentum injuries.

(b) Late results.

(i) Cardiac and great vessels.

(ii) Pulmonary fibrosis and 'frozen' chest.

(iii) Pleural reactions.

(iv) Diaphragmatic hernias.

Impact injuries (when force is directly applied to the chest wall) are caused by the patient being thrown against a portion of the vehicle, usually the windscreen, dashboard, steering wheel, or on to the roadway. Momentum injuries are caused by rapid deceleration without any direct impact injury and are seen in travellers who are held in place by a restraining harness. It is thought that the inherent inertia of the movable intrathoracic 
viscera causes these injuries by stress forces occurring at the attachment of the free and fixed points of the movable viscera.

\section{Impact Injuries}

Force transmitted from a localized impact may affect one or all of the following-chest wall, pleura, lungs, mediastinum or heart. To consider them anatomically:

\section{Chest Wall}

Many of the patients admitted, suffering from chest injuries, are shocked and as a consequence of the multiple injuries these patients are radiographed in the supine position. It is important to appreciate that the radiological appearances differ considerably from those usually seen in the conventional erect position. Failure to appreciate this will lead to grave errors in interpretation and consequent delays in diagnosis.

Fractures of the ribs are the commonest finding in impact injuries and the extent of damage is of course proportional to the force, the nature of the impact point and the physical nature of the impact object.

In assessing the extent of rib damage it is important to look for double fractures of the ribs, as (Fig. I) ribs thus detached frequently result in paradoxical movement of the chest wall (flapping chest wall) with the consequences of respiratory embarrassment with considerable extrapleural hæmatoma and hæmorrhage into the soft tissues. This soft tissue density may make the detection of the second rib fracture more difficult and later unsuspected paradoxical movement may develop. It is important that these double fractures be not overlooked as paradoxical movement may develop relatively quickly during the recovery from shock and cause considerable embarrassment to respiration (Figs. 2a and $2 b$ ).

Equally, pleural exudates and extra-pleural hæmatomata may contribute to the loss of translucency over the affected side of the chest and this loss of translucency must not be misinterpreted as due to intra-thoracic changes.

Steering wheel trauma is probably the most frequent 'impact source' in deceleration injuries in motor vehicles, and when the fractures of the sternum occur in association with other injuries they may be overlooked. In the postero-anterior view sternal fractures may be difficult to recognize and localized lateral films are essential in every case when impact injury has involved the sternum. Retrosternal hæmatoma, associated with sternal fracture, may appear as soft tissue shadows in the retro-sternal space and may be the first radiological indication of sternal fractures.

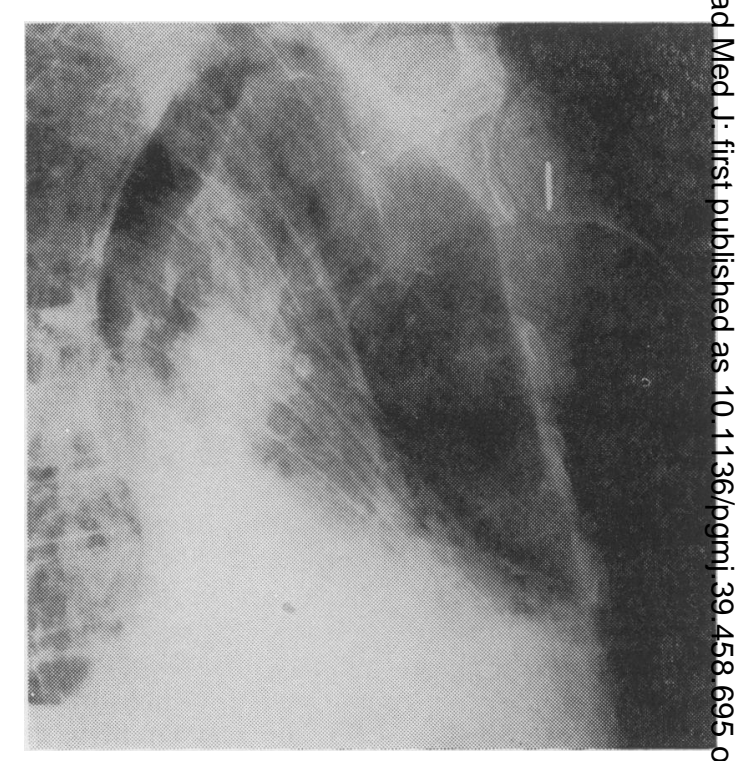

FIG. I.-Double rib fractures. A male, aged 65, who was knocked down by a motor car and sustained left rib fractures, dislocation of the sterno-clavicula joint and a fractured scapula. The left side of the chest was flattened but no paradoxical movement was present; 24 hours later paradoxical movement and carbon dioxide retention developed. Th\& oblique film shows the double rib fractures wheh gave rise to the unstable chest wall.

\section{Pleural Changes}

Associated with fractures of the ribs there map be quite extensive extra-pleural hæmatomata iâ the soft tissues of the thoracic wall which max cause a diffuse loss of translucency throughout the lower part of the hemithorax. Tangential view will show the extent of this hæmatoma and the inward displacement of the parietal pleura. IE should be remembered that such hæmatomata immobilize the chest wall and may result in considerable splinting and restriction of movement This may be associated with a considerable functional impairment in this portion of the lung

Pleural or lung penetration by ribs may be् associated with a considerable effusion of blood and air into the pleural cavity. As it is importan? to assess the extent and aspirate this bloodstained effusion before organization occurs such effusions must be carefully looked for. If the patient can be rotated into the decubitus position (unfortunately this is frequently not possible) a relatively smale quantity of fluid in the pleural cavity can be demonstrated. Differentiation of the extrapleuraf hæmatoma from an intrapleural hæmorrhage may be difficult during the early stages after injury and? there are no guiding $\mathrm{X}$-ray signs at this stage. If;O however, the patient can sit up, it is possible too differentiate intrapleural fluid from extrapleural by 


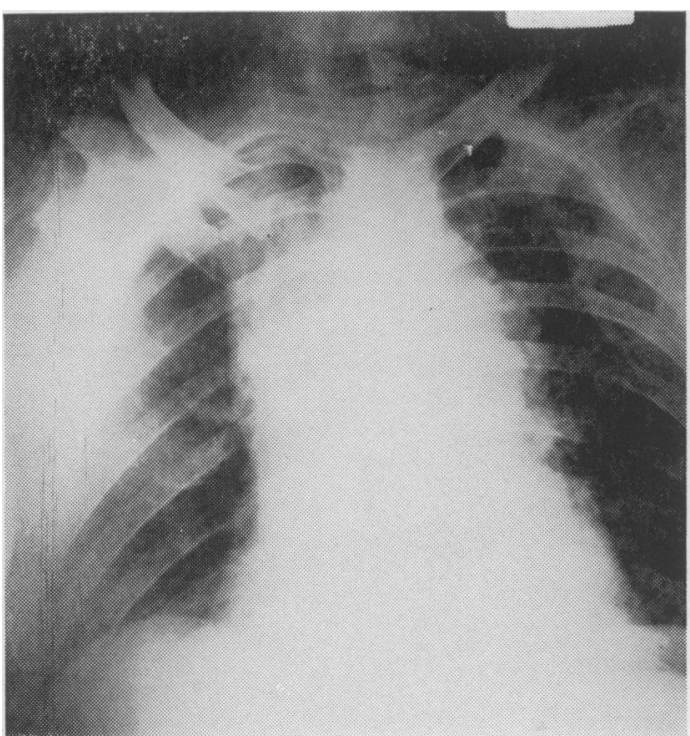

FIG. $2 a$.

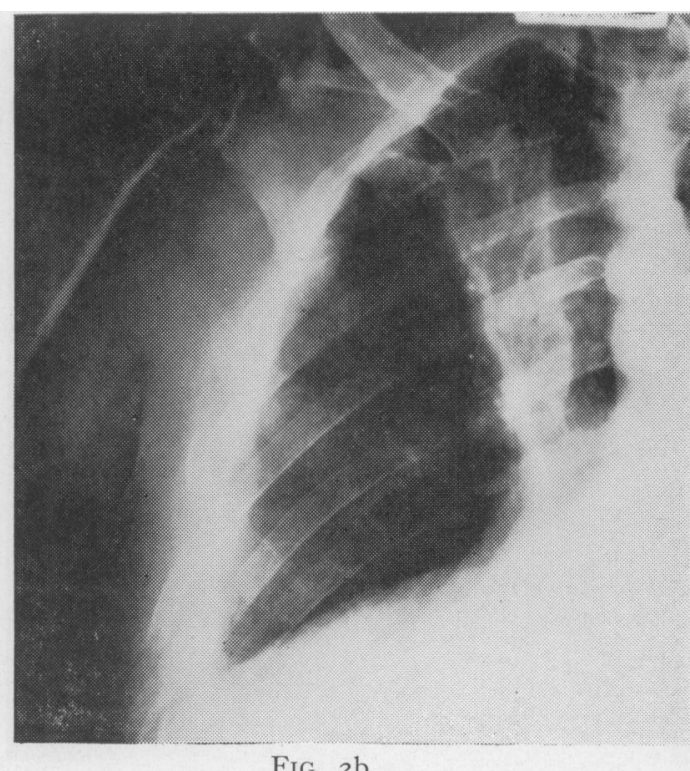

Fig. 2b.

FIG. 2.-Flapping chest wall and mediastinal homatoma. Admitted with a crushed chest. Tracheostomy was performed and the patient hand-ventilated on admission, treated by I.P.P.R. for several days. During hospital stay developed collapse of the right lower lobe. Fig. 2a demonstrates the gross widening of the upper mediastinal shadow; the extensive soft-tissue shadowing over the lateral chest wall largely obscures the rib damage. Fig. $2 \mathrm{~b}$ shows, in the oblique position, the double fracture of the ribs.

the appearance of the upper curve of an effusion or a fluid level if a hæmopneumothorax is present (Fig. 3).

Penetration of the lung by a fractured rib may result in pneumothorax or surgical emphysema (Figs. $4 \mathrm{a}$ and $4 \mathrm{~b}$ ), with or without an effusion into the pleural cavity. Air in the pleural cavity producing a pneumothorax may be easily overlooked in the early stages when the film is taken in the supine position. In this position the air rises to the anterior part of the chest and the air-filled lung lying behind the free air obscures the pneumothorax (Figs. 5a and $5^{\mathrm{b}}$ ). Lateral films of the chest with a horizontal ray at this stage are of importance in diagnosis and show the air lying anteriorly.

It should be appreciated that surgical emphysema may occur without any obvious pneumothorax. The presence of surgical emphysema implies lung damage, usually by penetration from a fractured rib. It is equally important to realize that its absence does not imply absence of penetration as the reflex splinting of the chest wall may result in the surgical emphysema not appearing until a few days after injury. The association of surgical emphysema and fluid in the soft tissue may result in the appearance of a ' cavity with a fluid level' in the extrapleural soft tissues which may overlap the lung field and cause errors in interpretation.

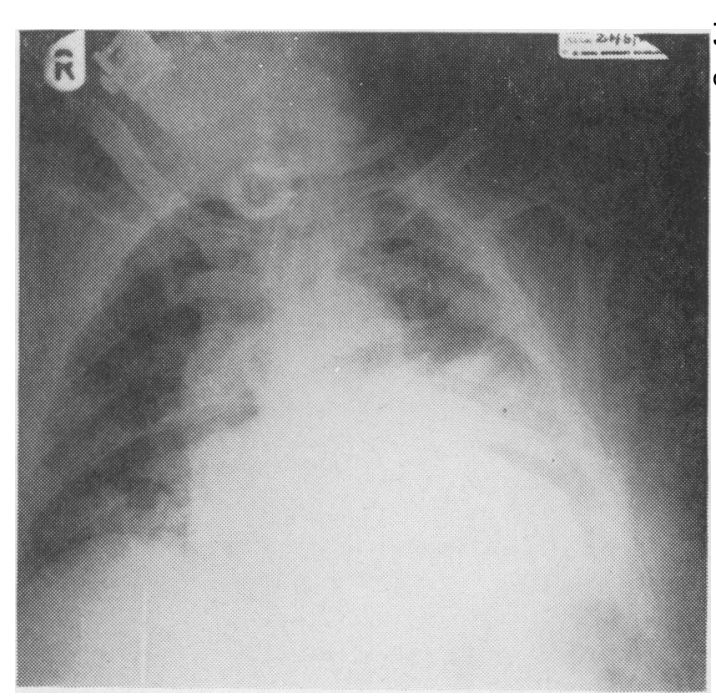

FIG. 3.-Fluid in supine position. A male, aged 68, struck on left side of chest as he was propelled forwards against the passenger seat. He showed bruising over the whole of the left side of the chest and renal area. Paradoxical movement was present but he was not unduly distressed. Tracheostomy was performed after carbon dioxide retention had developed in the next 24 hours. He was put in a Barnet ventilator and kept in a mechanical respirator for six days. Fig. 3 shows the diffuse loss of translucency over the left lower chest. One half-pint of blood was aspirated from the left chest at this tıme, 


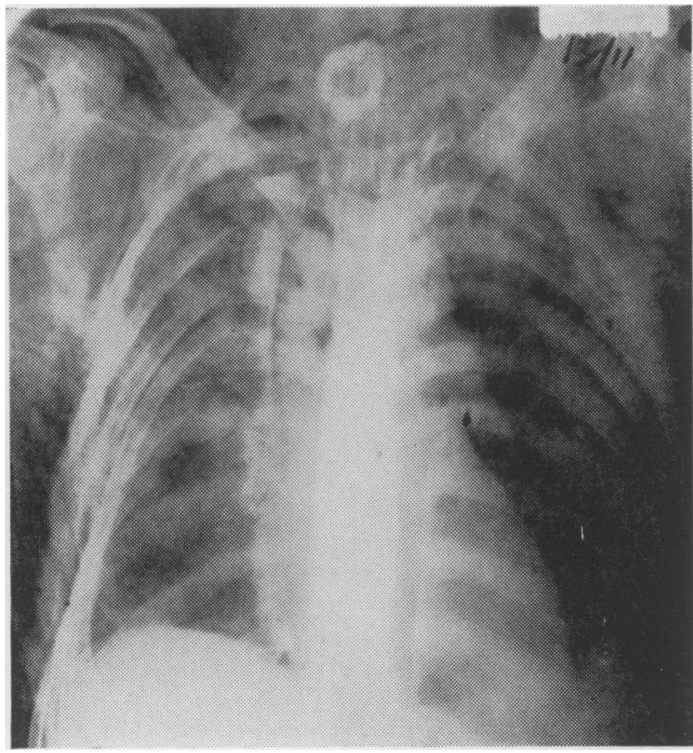

Fig. 4a.

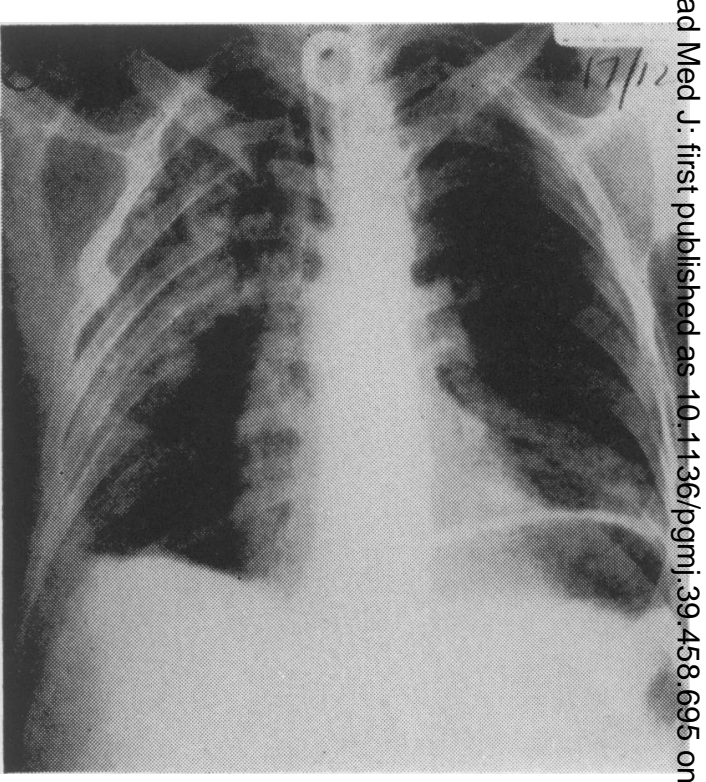

Fig. 4b.

Surgical emphysema. Fig. 4a: Extensive emphysema developing after bilateral rib fractures following a deceleratio injury. Artificial ventilation may greatly exaggerate the degree of surgical emphysema that develops. Fig. 4b shows rapid resolution of the surgical emphysema within five days. The fractured ribs can now be clearly seer $\frac{\mathbb{S}}{3}$

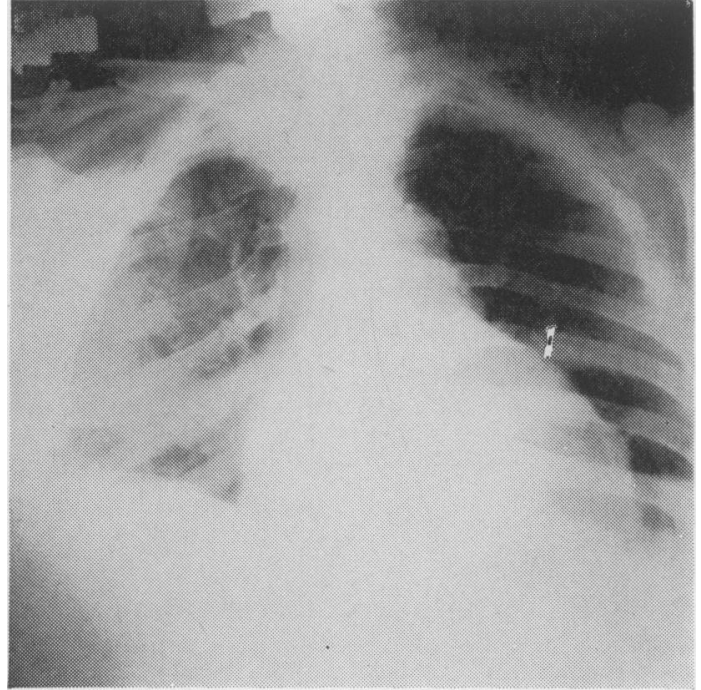

Fig. 5a.

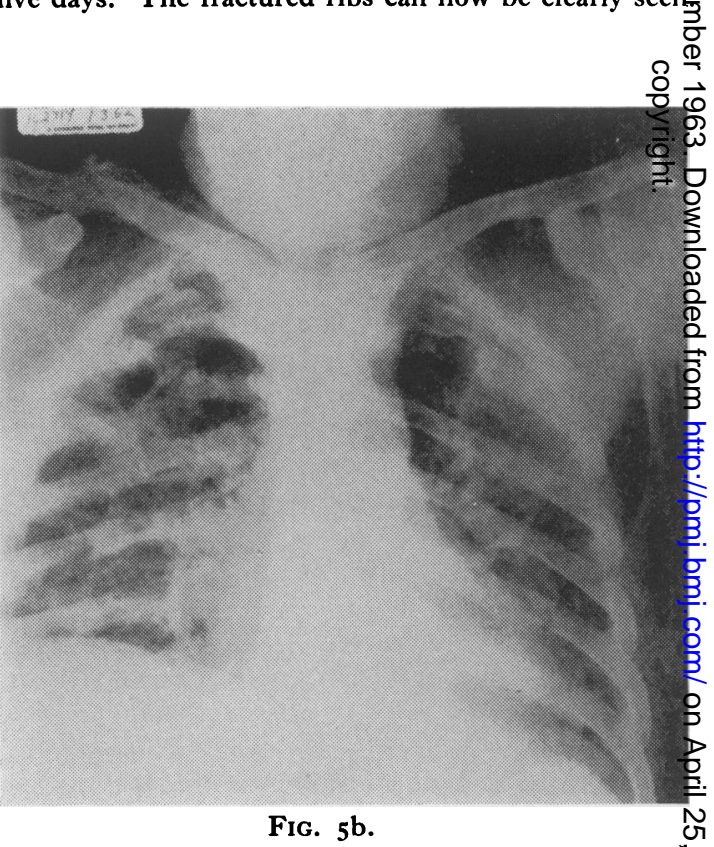

Fig. 5b.

Pneumothorax. Male, aged 54, who received multiple injuries after a bicycle/car accident. Transfused with 4 pints of blood; a tracheostomy was performed and a Barnet respirator brought into use. Fig. 5a shows left-sided pneumgo thorax but no appreciable mediastinal shift. An effusion is also present on the right side. Fig. $5 \mathrm{~b}$ : Rapid re-expansiofs of the left lung has occurred. The rib fractures and the effusion on the right side are now clearly visible.

Mediastinal emphysema and pericardial emphysema may occur during the early stages of a sudden chest injury and it is important that air in these areas is not overlooked, as both these conditions may give rise to marked venous obstruction. Although at first sight this ma 
appear unlikely, when the radiological picture is confused by extensive surgical emphysema such collections of air may be overlooked.

\section{Pulmonary Damage}

In children and young adults the thoracic wall is extremely elastic and it may be possible to compress the lung and give rise to lung damage without any chest wall damage. In the older age group when the bony thorax is rigid such damage is unusual without concomitant rib injury.

'Contusion' of the lung field can be extremely difficult to differentiate from the appearances caused by deflation or atelectasis of the lung, which may also follow trauma and appear either as segmental areas giving rise to opacities of varying size or patchy opacities arising from areas of lobular collapse. As much of the pathological change in lung contusion consists of patchy atelectasis associated with extravasation of blood, lung contusions usually resolve relatively quickly and within a few days the radiographic picturc returns to normal.

Pulmonary hæmatoma is a less common finding and results in a localized collection of blood in the lung. The fate of a pulmonary hæmatoma is vastly different from that of a lung contusion and while resolution of the latter is relatively rapid the hæmatoma may persist for several weeks (Figs. $6 \mathrm{a}$ and $6 \mathrm{~d}$ ). In the early stages the diffuse opacity becomes more circumscribed and may show a well-defined wall. At this stage it has to be differentiated from a localized collection of fluid in the interlobar fissures and this can be done on a careful consideration of its anatomical basis. Frequently during the phase of resolution 'a tail' will appear in the opacity which will enable a loculated effusion to be differentiated from a pulmonary hæmatoma. Rarely, too, a fluid level may form during a phase of resolution of the pulmonary hæmatoma. Milne and Dick, (1962) in recording 15 cases of pulmonary hæmatoma due to different causes, have clearly shown how this may occur with relatively mild chest injuries.

\section{Mediastinal Hamatoma}

As many of the radiographs in the early stages after injury are taken with portable units using a short-distance technique, the importance of widening of the mediastinum may be overlooked. However, when the films can be taken with the more orthodox technique blurring of the mediastinal edges associated with loss of sharpness of the mediastinal outlines and increase in width should suggest the diagnosis.

Hæmatomata occurring in the posterior mediastinum are usually associated with fractures of the vertebral bodies and their recognition in the postero-anterior film will draw attention to the need for a full investigation of the dorsal spine. This can be recognized in the postero-anterior view by the widening of the paravertebral line and a soft tissue mass indicating a mediastinal hæmatoma.

Hæmatoma in the 'middle mediastinum' has a more serious prognostic significance, arising from injuries to the great vessels, and these will be dealt with under momentum injuries.

The clinical symptoms of mediastinal emphysema vary considerably - they may be completely absent or they may give rise to venous obstructive symptoms or even symptoms of dyspnoea or dysphagia.

The perennial problem in chest trauma is the detection of superadded pulmonary infection. Radiologically an extension of collapse following localized bronchial obstruction or even patchy collapse following patchy bronchial obstruction may result in appearances which have to be differentiated from a superadded infection. Staphylococcal infection may produce areas of patchy opacity in both lower lobes, which may mimic any of the above features. The rapid appearance of these diffuse patchy opacities in both bases within a few days after the injury should suggest the possibility of a staphylococcalo infection.

\section{Momentum Injuries}

Momentum injuries are considered to be caused in two ways: first, by a shearing force produced by the inertia of a mobile viscus tearing it from a more fixed attachment, e.g. aortic rupture and thoracic duct rupture; secondly, a pressure effect caused by an alteration in thoracic pressures, e.g. bronchial rupture, pneumothorax, and even diaphragmatic rupture. It must be accepted, however, that diaphragmatic ruptures associated with rib fracture and penetration of the diaphragm are far more common.

To deal with each type on an anatomical basis; laceration of the lung most frequently follows rib injury with penetration of the lung and as such is invariably associated with a degree of pulmonary contusion and escape of air into the tissues or into the pleural cavity. The appearance of surgical emphysema usually indicates some degree of pulmonary laceration but if the pleural space is previously sealed surgical emphysema may appear without any evidence of a pneumothorax.

Torsion of the lung is a rare condition where the whole lung rotates around the hilum. It is an excessively rare finding and only occurs when a pneumothorax is present. In the cases which have been recorded a fairly characteristic X-ray appearance of the pulmonary blood vessels is seen 


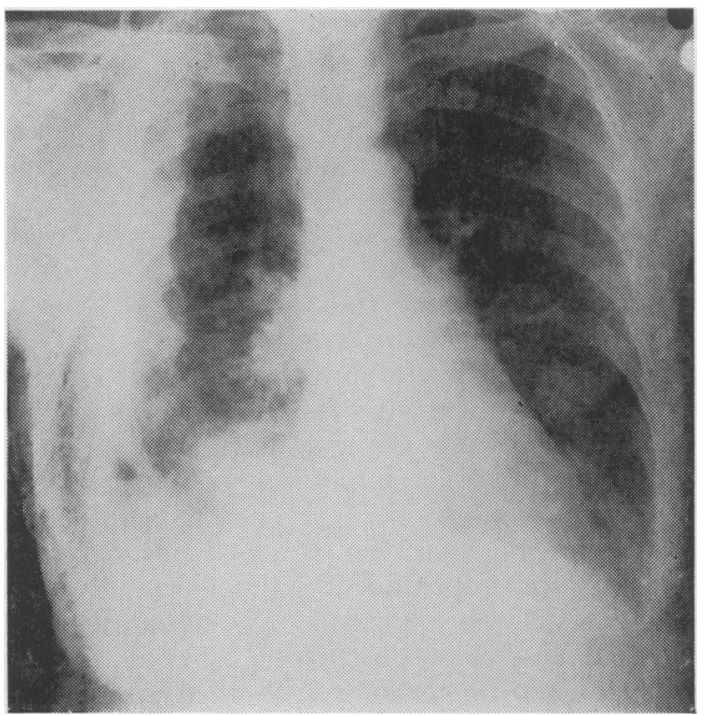

FIG. 6a.

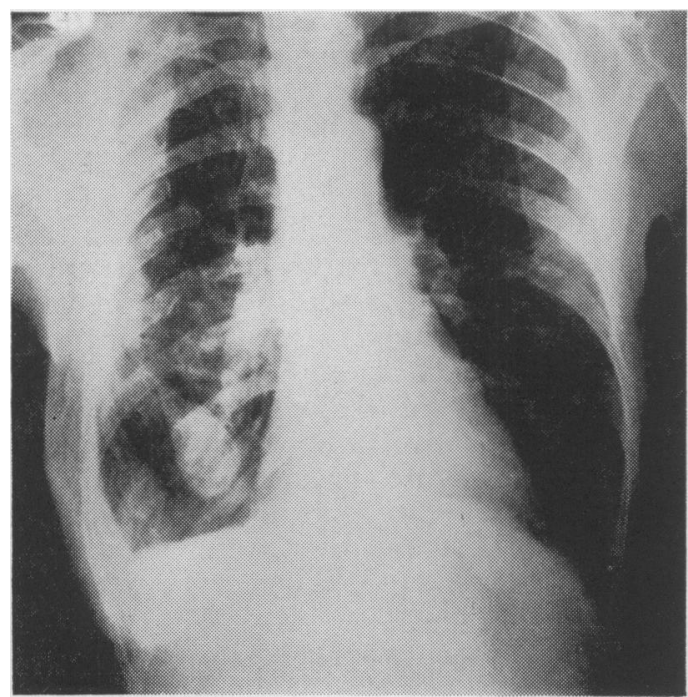

FIG. 6c.

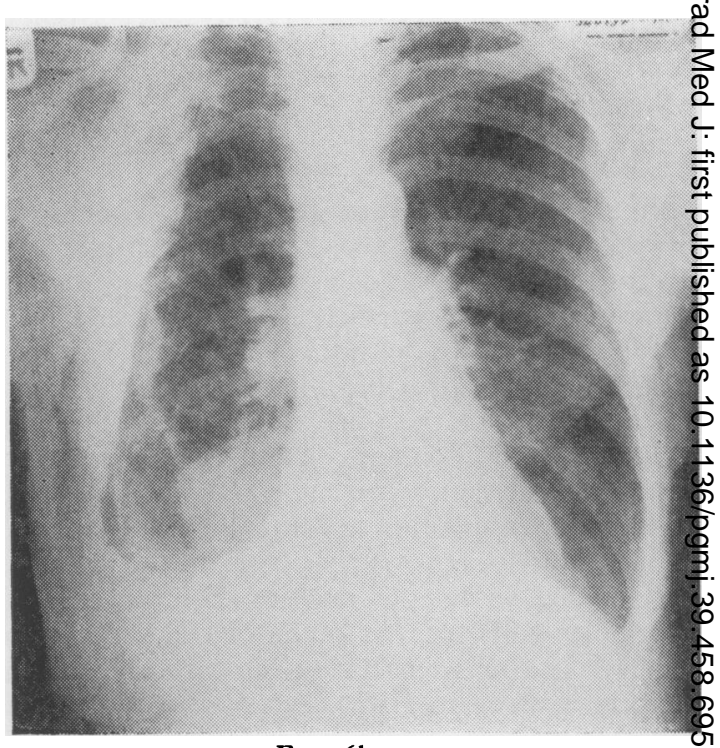

FIG. 6b.

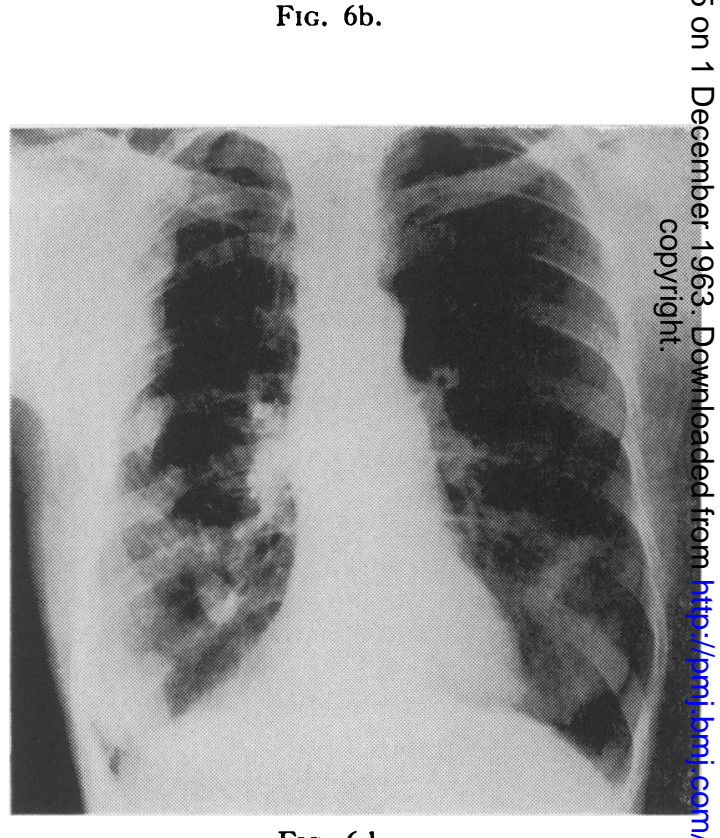

Fig. 6d.

Pulmonary contusion and pulmonary hamatoma. Female, aged $6_{3}$, who was knocked down by a bus. Paradoxical breathin present on admission and gross surgical emphysema of chest wall and ribs. Fig. 6a: A pneumothorax was als present. An underwater drain was put into the left pleural cavity and she was kept in a Barnet ventilator for 24 . hours (Fig. 6b). Fig. 6c shows the disappearance of the shadowing from the right base and the underlying pufo monary hæmatoma is more clearly seen. Fig. 6d shows the appearances nearly four months after the originas injury. The hæmatoma is still clearly visible although considerably smaller in size.

in which the upper lobe vessels sweep downwards towards the base, indicating that torsion of the lung has occurred.

Bronchial rupture is a more common finding than torsion and is almost always the result of altered intrabronchial pressure as the result of momentum injury. The diagnosis of a bronchia rupture is of the utmost importance, as surgical repair of the torn bronchus may be feasible, and on the plain film there may be few radiological 


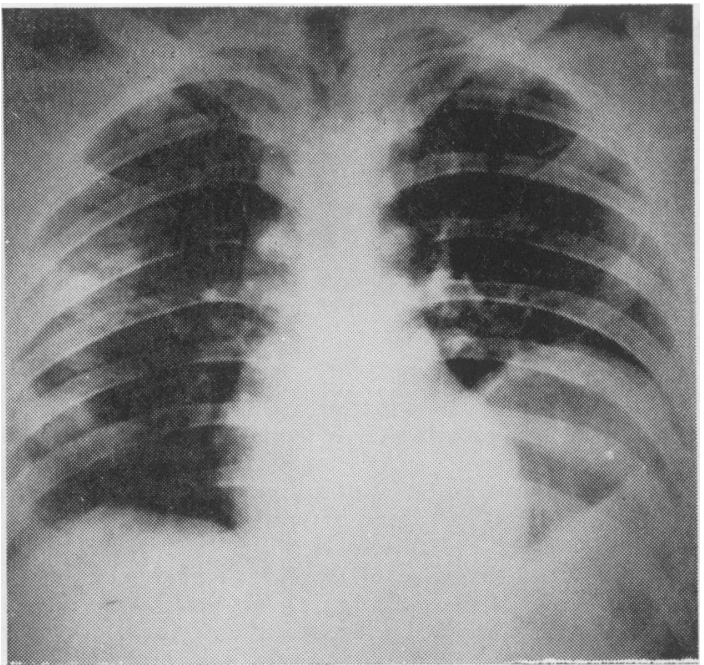

Fig. 7a.

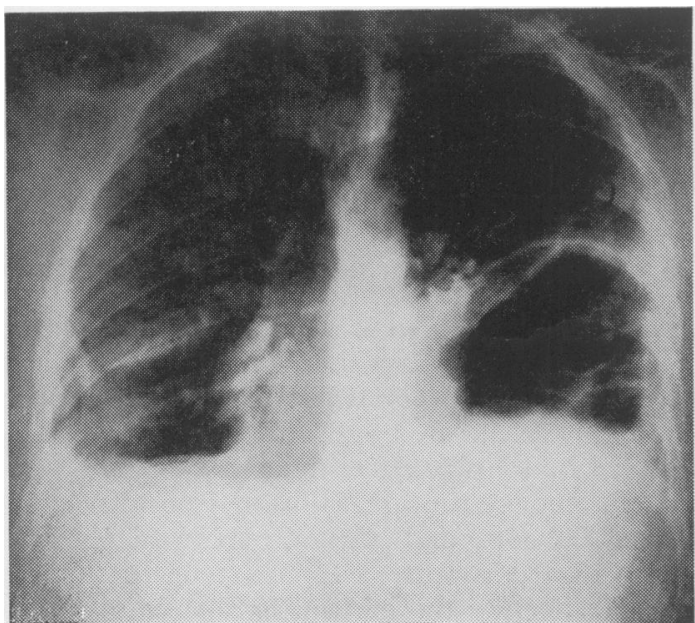

Fig. 7c.

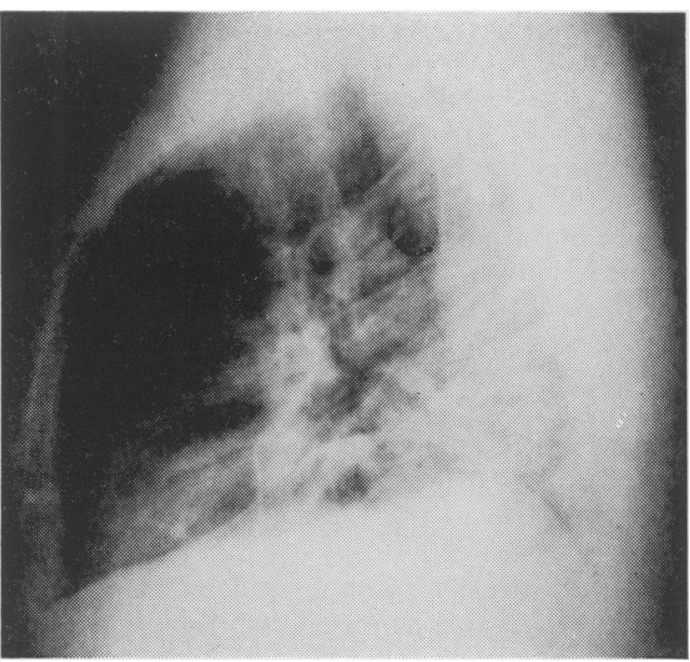

FIG. $7 \mathrm{~b}$.

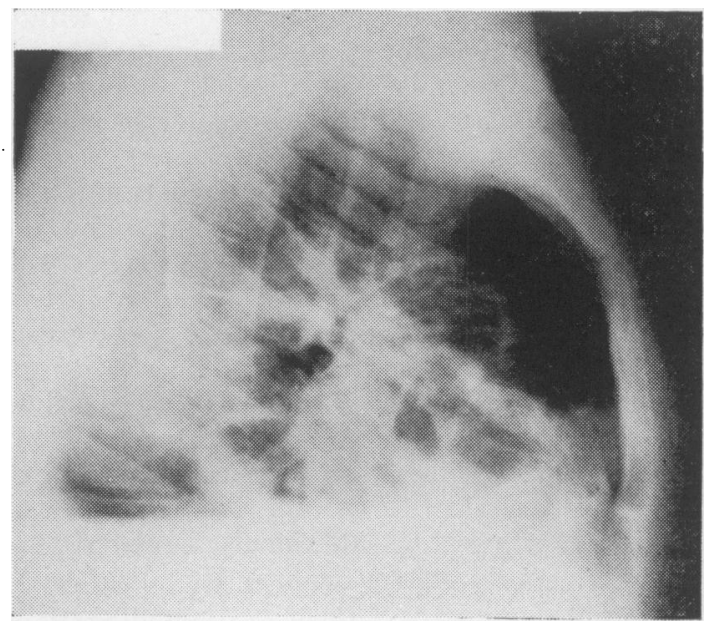

FIG. 7d.

Traumatic rupture of left diaphragm. Figs. $7 \mathrm{a}$ and $7 \mathrm{~b}$ show a postero-anterior and lateral view of the chest of a patient following admission. The left diaphragm is raised but it is difficult to decide what structures have herniated. Figs. $7 \mathrm{c}$ and $7 \mathrm{~d}$ : Postero-anterior and lateral views 24 hours later; the herniated bowel with its gas-filled shadows is clearly seen.

signs. A pneumothorax, subcutaneous or mediastinal emphysema may be the only signs noted and collapse or obstructive emphysema may not be seen in the affected lung. The presence, however, of mediastinal emphysema and a pneumothorax should call for immediate bronchoscopic investigation. The pneumothorax is frequently a tension one, and was as high as $42 \%$ in Kinsella and Johnstrud's series (1947). After initial treatment has been performed bronchography should always follow bronchoscopic examination to check that any other small ruptures have not been overlooked.

\section{Thoracic Duct}

The development of a massive effusion after a closed chest injury in the absence of rib injury should suggest the possibility of a chylothorax, secondary to rupture of the thoracic duct. The chylothorax for anatomical reasons is usually right-sided, as that portion of the duct usually involved in vertebral fractures is its lowermost 
portion which is in closest contact to the vertebral bodies.

The exact mechanism of rupture is not known but it is of interest that the reported cases are frequently associated with a fracture of the dorsal spine. In such cases the injury is probably a direct one from the affected vertebra, as the duct courses along the side of the vertebral column.

Clinically there is usually a delay in the appearance of symptoms although the fluid may be visible on the immediate $\mathrm{X}$-ray. It may be that the gradual process of accumulation allows symptoms initially to be slight and to develop only when the cffusion has become massive.

\section{Diaphragmatic Injuries}

It has already been mentioned that the diaphragm may be ruptured by direct penetration from a fractured rib but equally it may be ruptured as the result of a raised intrathoracic pressure.

In the films taken immediately after injury and for the first 24 hours the diaphragm may be elevated as a sign of fractured ribs without necessarily any damage to the elevated leaf of diaphragm. Its raised position as an indication of diaphragmatic rupture consequently may not be appreciated (Figs. $7 a$ and $7 b$ ).

Herniation of abdominal contents through the diaphragm may be readily detected when they consist of gas-filled loops of bowel, but solid viscera, like liver, spleen or even kidney, may be more difficult to recognize. Tilting of the patient into the Trendelenburg position may exaggerate the degree of herniation of a solid viscus through the diaphragmatic rent and this is especially liable to occur on the right side when the right diaphragm is involved.

In the context of additional manœuvres that may be employed to confirm the diagnosis of ruptured diaphragm it must be remembered that a pneumoperitoneum is not necessarily diagnostic, as in some cases the diaphragmatic rupture may be associated with an intact parietal peritoneum and pneumothorax may not necessarily follow the induction of a pneumoperitoneum.

The importance of a ruptured diaphragm should not be overlooked as this type of hernia has a marked tendency to strangulate and should be submitted to surgery as soon as the diagnosis has been made.

Herniation through the diaphragms can be more readily appreciated by examination of the patient in the Trendelenburg position during the Valsalva manœuvre. Administration of barium to outline and identify the bowel assists in the diagnosis and solid viscera are more readily identified.

According to Carter, Guiseffi and Felson (195I),
$90 \%$ of diaphragmatic herniæ which strangulare are traumatic in origin and according to the authors this is due to the relatively small tear in the diaphragm through which the abdomina! viscera protrude. This narrowed opening at the site of herniation predisposes to strangulation the neck of the hernia. Screening the diaphrag $\underline{\underline{\underline{\underline{m}}}}$ is not significant, as apparently normal moveme of the diaphragm may be seen even with extensige ruptures.

The following case illustrates the findings in a rup tured diaphragm with the development of a traumatic hernia. The patient, a male, aged 20 years, was injured in a motor-car accident and suffered an impact injug on the right side of the chest with the development $6 \mathrm{f}$ a pneumothorax and fractured ribs. Early films of the chest show an elevation of the left diaphragm (Fig. and 7 b), but no definite bowel shadows can be seg above the diaphragm. Films 24 hours later, howevef, reveal extensive herniation of bowel through the dio phragm and both large and small bowel coils can be seigp.

Repair was carried out by Mr. Logan, who fouk coils of congested jejunum in the left pleural cavity and also a portion of the transverse colon. Reduction and repair was undertaken and the subsequent films showed the diaphragm in normal position. As the major injugy was on the right side of the chest and no bony injury was present on the left side the presumption is that the rupture of the left diaphragm was due to altered pressure.

\section{Heart and Aorta}

Aortic rupture, or rupture of one of the gregt vessels arising from the aorta, may occuf in deceleration injuries, either as an impact injuoy from direct violence or as a momentum injury, assa consequence of a shearing force. The latter \$s more likely to occur when the aorta and branches are diseased and atherosclerotic. Three types of injury may affect the aorta:-

I. Immediate rupture. This may occur near the root of the aorta and is usually immediately fat

2. Delayed rupture. In this type of rupture, usually affecting the aorta near the site of orig of a major vessel, a localized mediastinal hæmatoma seals off the initial rupture and leads to the develogment of a false aneurysm which ultimately rupturess either into the pleural cavity or into an adjoining viscus.

3. Traumatic aneurysm. Many authorities feèl that a traumatic aneurysm is merely an extension of the second type. It tends to have a longer history, however. Certain anatomical considerefr tions, related to the site of the aneurysm, suggesst that this type of injury is a momentum rather the an impact injury. A traumatic aneurysm usuafy occurs in the descending aorta at its junction with the aortic arch, and this is in fact the site at which the movable part joined the fixed part of t descending aorta. A transverse intimal tear may develop at this point and a false sac then develogs as the result of hæmo-dynamic forces. 


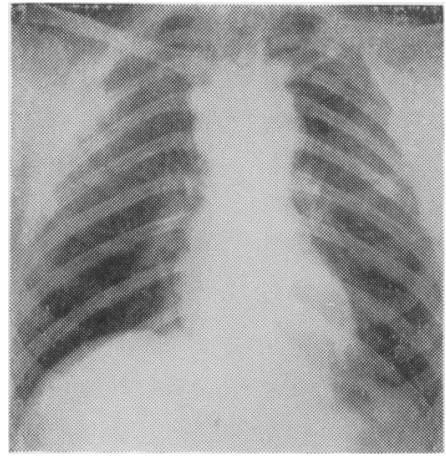

FIG. 8a.

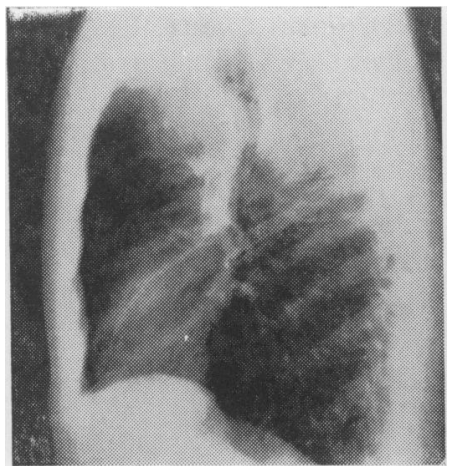

Fig 8b.

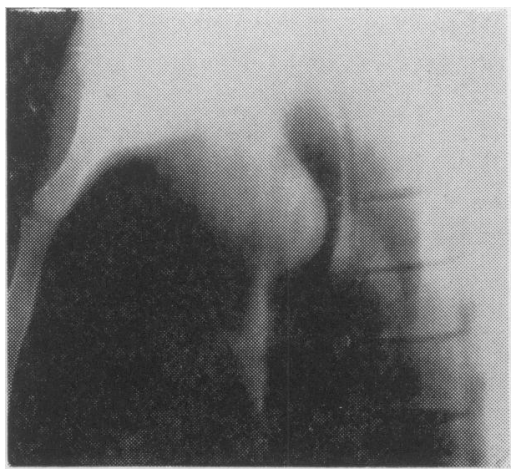

Fig. 8c.

Traumatic aortic aneurysm. A man who has been involved in a motor-car accident with a deceleration-impact-type injury. After a stormy convalescence he remained well until routine pre-employment examination showed a shadow present in the superior mediastinum (Fig. 8a). The lateral film shows the trachea to be displaced backwards and the lateral tomograph $(8 \mathrm{c})$ reveals the extent of indentation. Angiograms demonstrated the mass to be aortic in origin.

The recognition of traumatic aneurysms is important as its natural history is one of steadily increasing growth, ultimately leading to rupture. As the majority of these aneurysms are saccular in origin surgical repair should be possible in most cases.

An example of such an aneurysm is shown in Figs. $8 \mathrm{a}$ to $8 \mathrm{c}$. The patient was a young male who was involved in a motor-car accident and suffered a deceleration injury with impact-type fractures of his sternum and clavicle. From these he ultimately recovered but at a routine pre-employment $\mathrm{X}$-ray examination of his chest it was noted that a soft tissue swelling in the superior mediastinum was present. Further investigation by tomography revealed that a compression of the anterior wall of the trachea was present.

In view of the site it was considered that the condition most probably represented a traumatic aneurysm. A venous angiocardiogram was performed and it was noted that the 'mass' filled with dye, but that the origin of the innominate vessel could not be seen. Surgical attempts to reconstitute the aortic arch under hypothermia were unsuccessful and the innominate vessel had to be sacrificed; the patient succumbed 24 hours after operation. The aneurysmal sac at operation was extremely friable and the delineation of an anatomical plane from the mediastinal structures was impossible.

\section{Cardiac Injuries}

Kissane reported $15 \%$ of fatal chest injuries to be due to heart trauma and the incidence of cardiac injuries has been reported as between $2.6 \%$ to $18.5 \%$. Barber (1940) noted abnormal electrocardiograms in eight of 32 patients who had sustained non-penetrating thoracic trauma. It is possible, however, that functional changes are far more frequent and serious cardiac arrhythmias may occur which seriously endanger the patient's life.
The lesions of the heart that can be shown radiologically after deceleration injuries are hæmopericardium and pericardial effusion; later, calcified pericardium may develop as a sequel. Myocardial aneurysm and rupture of the cardiac septum have also been demonstrated.

Intracardiac damage following deceleration injury may occur in adults but it is in the younger age-group, where the chest wall is mobile, that injuries to the heart far more frequently occur. Desforges and Abelmann (1963) report rupture of the interventricular septum in a 15 -year-old youth who suffered from a deceleration impact injury (steering-wheel) following a motor-car accident. These authors postulate a hæmatoma formation in the inter-ventricular septum as the precursor to the development of a defect at a later stage. Carey, Hurst and Arentzen (1958) also report 4 cases of interventricular septal rupture secondary to trauma and stress the importance of recognition of these cases as they can be dealt with surgically.

The defect developed in the muscular portion of the septum and in the case reported, was repaired surgically. Rupture of the interventricular septum appears to be the commonest intracardiac injury following impact injuries. Recognition of such cases is important as surgical repair is possible.

\section{Pericardial Effusion}

The development of a traumatic pericardial effusion is a well-known fact, (Wolff and Grunfield, 1963) and should be borne in mind when any appreciable increase in cardiac size occurs rapidly after an accident. 
The possibility of cardiac tamponade from hæmorrhage into the pericardium is far greater after a penetrating injury of the chest, and may or may not be associated with sternal injuries. The X-ray features are no different from those of other pericardial effusions but (with rapid bleeding) severe cardiac tamponade can be present without any material alteration in cardiac size. Myocardial infarction following trauma has been reported (Barber, 1940). The most probable sequence of cvents associated with myocardial infarction occurring after injuries is prolonged shock and hypotension which may have a greater influence on the devclopment of thrombosis than actual trauma to the cardiac wall.

The possibility of the appearance of a delayed hæmopericardium must not be overlooked and enlargement of the cardiac outline may not occur until later. The radiological features are no different from those occurring in the early stage of the disease but as the blood collects at a slower rate, the cardiac outlines may show a far greater enlargement with fewer clinical symptoms.

\section{Summary}

I. The different types of intrathoracic injuries occurring after injury are discussed.

2. The importance of recognising the types injuries which may follow direct violence (impa injuries) and those which follow closed injug (momentum injuries) is considered.

3. The basic principles in the interpretation $\overrightarrow{\theta f}$ the radiological features of pulmonary injuries are discussed.

4. The radiological features of cardiac injuriss following non-penetrating trauma are considere

I am indebted to Dr. Robertson and Dr. Griffiths for access to their records and for generously allowifig me to quote from their cases. I must also thank N. A. Logan and Mr. B. LeRoux for allowing me peo mission to quote from the cases under their care.

\section{REFERENCES}

Barber, H. (1940): Contusion of Myocardium, Brit. med. F., ii, 520.

Braunstein, P. W. (1957): Medical Aspects of Automotive Crash Injury Research, F. Amer. med. Ass., r63, 249.

Carter, B. N., Guiseffi, J., and Felson, B. (1951): Traumatic Diaphragmatic Hernia, Amer. F. Roentgenol., 65 59 .

CARY, F. H., Hurst, J. W., and ARENTZEN, W. R. (1958): Acquired Interventricular Septal Defect SecondarQ to Trauma, New Engl. F. Med., 258, 355 .

Desforges, G., and AbelmanN, W. H. (r963): Interventricular Septal Defect Due to Blunt Trauma: Report $\mathrm{J}^{\mathrm{f}} \mathrm{e}$ Case Repaired Surgically Under Total Cardiopulmonary Bypass, Ibid., 268, I 28.

Kinsella, T. J., and JohnsRud, L. W. (1947): Traumatic Rupture of Bronchus, $\mathcal{F}$. thorac. Surg., r6, 57 I.

Kissane, R. W. (1952): Traumatic Heart Disease: Nonpenetrating Injuries, Circulation, 6, 421.

Livingstone, R. G. (1954): Automobile Collision Injuries, Surgery, 36, 1059.

Milne, E., and Dick, A. (1961): Circumscribed Intrapulmonary Hæmatoma, Brit. F. Radiol., $34,587$.

Wolff, L., and Grunfield, O. (196.3): Pericarditis, New Engl. F. Med., 268, 419.

Woodward, F. D. (1957): General Medical Aspects of Automobile Crash Injuries and Deaths, $\mathcal{F}$. Amer. med. A 163,225 . 